\title{
Genetic and Epigenetic Traits as Biomarkers in Colorectal Cancer
}

\section{Marianne Berg ${ }^{1, *}$ and Kjetil Søreide ${ }^{1,2}$}

1 Department of Surgery, Stavanger University Hospital, P O Box 8100, N-4068 Stavanger, Norway

2 Department of Surgical Sciences, University of Bergen, 5021 Bergen, Norway;

E-Mail:ksoreide@mac.com

* Author to whom correspondence should be addressed; E-Mail: marianne.berg@sus.no; Tel.: +47-51-51-80-00; Fax: +47-51-88-08-95.

Received: 17 October 2011; in revised form: 28 November 2011 / Accepted: 7 December 2011 / Published: 16 December 2011

\begin{abstract}
Colorectal cancer is a major health burden, and a leading cause of cancer-related deaths in industrialized countries. The steady improvements in surgery and chemotherapy have improved survival, but the ability to identify high- and low-risk patients is still somewhat poor. Molecular biology has, over the years, given insight into basic principles of colorectal cancer initiation and development. These findings include aberrations increasing risk of tumor development, genetic changes associated with the stepwise progression of the disease, and errors predicting response to a specific treatment. Potential biomarkers in colorectal cancer are extensively studied, and how the molecular aberrations relate to clinical features. Yet, little of this knowledge has been possible to transfer into clinical practice. In this review, an overview of colorectal cancer genetics will be given, as well as how aberrations found in this tumor type are proposed as biomarkers for risk prediction, as diagnostic tools, for prognosis or prediction of treatment outcome.
\end{abstract}

Keywords: biomarker; colorectal cancer; mutations; epigenetics; microsatellite instability; chromosomal instability; risk marker; diagnostic marker; prognostic marker; predictive marker

\section{Introduction}

Colorectal cancer (CRC) is a major health burden in the western world. The disease normally develops from a benign polyp through an adenoma with dysplasia into a carcinoma with metastatic potential. The high incidence combined with high mortality from the disease if diagnosed at a late 
stage, signifies the need for better diagnostic, prognostic and predictive tools. The emergence of knowledge on the molecular level has gained insight in causes for initiation and progression of tumor development. This knowledge has also revealed the complexity and heterogeneity of the disease, explaining why few biomarkers are in routine clinical use.

Cancers arise as a result of genetic and epigenetic alterations accumulating in a cell [1]. These changes lead to dysregulation of fine-tuned pathways, and thereby disturb the normal proliferation and growth of the cell. Predominantly, colorectal cancer arises sporadically, although a smaller subgroup arises either as a result of inherited mutations, or as a result of inflammatory bowel disease (IBD; Crohn's disease or ulcerative colitis).

Roughly, three molecular subtypes of colorectal carcinomas (CRC) are described based on molecular characteristics of the tumor; microsatellite instability (MSI), chromosomal instability (CIN), and $\mathrm{CpG}$ island methylator phenotype (CIMP). In addition, all of these three subgroups have mutations in protein coding genes, as well as impaired gene functions, and changes in expression of microRNAs (miRNA) that results in changes in gene expression.

Patient response to treatment is diverse, even if their disease seems similar when evaluating clinicopathological parameters. There is increasing evidence that treatment response is dependent on the normal genetic background of the individual in addition to aberrations in the tumor itself. Mapping the genetic defects in a patient tumor is yet of limited clinical importance, as the prognostic and predictive value is scarce. However, a large body of information about genetic aberrations underlying $\mathrm{CRC}$ has revealed complex and heterogeneous mechanisms underlying the occurrence of disease. This information is of the essence for understanding the disease behavior and related clinical outcome, and especially for future improvements in treatment and survival for the patients.

The current review article addresses some of the key concepts in CRC development, and outlines how genetic and epigenetic aberrations can be utilized as biomarkers for the disease in the future.

\section{Phenotypic Subgroups of CRC}

Chromosomal aberrations and aneuploidy are known as a hallmark of solid tumors. In colorectal cancers the large portion of the tumors display numerical chromosomal alterations, referred to as chromosomal instability (CIN) [2]. These CIN tumors have chromosomal composition which changes at a higher rate compared to normal cells, and recurrent gains and losses seem to affect chromosomes in a non-random manner [3]. The underlying cause(s) of CIN is to date not known, but alterations in mechanisms associated with chromosome segregation during mitosis are suggested [4,5]. The tumors in which mutations in microsatellites are demonstrated are referred to as microsatellite instabile (MSI) [6]. Tumors of the MSI phenotype have defects in the mismatch machinery, leaving errors introduced during replication unrepaired. Microsatellites are repetitive units, and therefore more prone to errors, and exist in both protein-coding and non-coding regions of the DNA. Deficient effect of mismatch repair genes has been found to cause this effect, either due to mutations in or as a result of hypermethylation of the promoter of these genes. Tumors harboring the latter of these aberrations have changes in the normal promoter methylation pattern. Methylation is chemical modification of DNA that leads to gene expression changes. This phenotype was discovered somewhat later than the CIN 
and MSI phenotypes, and named $\mathrm{CpG}$ island methylator phenotype (CIMP) [7,8]. As for the CIN phenotype, the underlying cause for CIMP is not revealed.

Initially, the CIN and MSI phenotype was thought of as mutually exclusive, but later found to be partly overlapping. The CIMP phenotype is largely overlapping with the MSI phenotype, and to some extent with CIN tumors. There is a small subgroup of tumors in which none of the phenotypes are detected, referred to as triple negative [9].

\section{Biomolecules}

The constant development and refinement of molecular techniques and knowledge about traits have increased our understanding of the human genome and its complexity in general, as well as cancer-specific aberrations. The total DNA content in a cell is referred to as the genome. The genes encoded by the genome are composed of both introns and exons, exons being the mRNA-encoding entities. The total content of mRNA in a cell at a given time point is referred to as the transcriptome. MicroRNAs (miRNA) are short RNA molecules that bind to complementary mRNA molecules, hindering the translation of the mRNA into a protein. In recent years both complete cancer genomes, transcriptomes, and exomes have been sequenced [10-12], DNA methylation profiles have been used to subgroup colorectal carcinomas [13], and even nucleic molecules such as microRNAs (miRNA) have been shown to play a role in cancer $[14,15]$. As non-protein-coding transcripts have been conserved throughout evolution, indicates that crucial functions exist for these molecules. For example, microRNAs (miRNAs) have been found to modulate several cellular processes [16]. The protein classes of RNA-binding proteins include essential regulators of miRNA biogenesis, turnover and activity. RNA-RNA and protein-RNA interactions are essential for post-transcriptional regulation in normal development and may be deregulated in disease. DNA, mRNA and miRNA are released and circulate in the blood [17]. Changes in the levels and types of circulating nucleic acids have been associated with tumor burden and malignant progression. Consequently, their potential role as markers of disease or risk for cancer is currently intensively investigated.

Faster and cheaper sequencing technology has made comparison of tumor exomes from patients with the same tumor type possible, helping the identification of cancer-driving mutations [12]. Also, comparison of primary tumor and the associated distant metastasis has aided the search for genes, which is important for the metastatic process or the progression of disease [18].

\section{Adenoma Carcinoma Sequence}

In colorectal cancer, adenomas are considered the most important precursor lesion for carcinomas, although a subgroup of hyperplastic polyps have also been shown to have malignant potential [19]. By the age of 70 years around $50 \%$ of the population has one or several adenomas presented in the colon. However, not all adenomas progress to carcinomas. The adenoma-carcinoma sequence suggests that specific mutations occur at specific stages, in order to transform the cell to a carcinoma with a metastatic potential. These mutations affect genes and pathways important for regulation of cell growth and differentiation.

The WNT pathway increases the proliferation rate in a cell when active, and is known as an early event in the adenoma-carcinoma-sequence [20]. The $A P C$ gene is thought to be the initial event 
transforming a normal cell into an adenoma, and is found in $\sim 80 \%$ of all colorectal carcinomas. If $A P C$ is mutated, the WNT signaling pathway is constantly on, even if WNT signal is absent, and the cell proliferates, Figure 1. Mutation in the oncogene $K R A S$ is another aberration seen both frequently $(\sim 40 \%)$, and early in the transformation of normal cells. Mutations in the oncogene $B R A F$, yet another gene in the MAPK pathway, are seen early in malignant transformation. Both KRAS and BRAF mutations will increase the proliferation rate in the cell, comparable to mutations in $A P C$. The $\mathrm{TGFb}$ pathway has been shown to be abrogated later in the development, transforming an intermediate adenoma to a late adenoma. Mutations in SMAD4, TGFBR2 or deletions at 18q are observed [21]. Mutations in the tumor suppressor gene TP53, or loss of $17 \mathrm{p}$ where TP53 is located, are observed in more than $50 \%$ of colorectal tumors, and as late events in CRC development. This high frequency of TP53 inactivity found in carcinomas, but not in adenomas, suggests TP53 to be pivotal for the malignant transformation of the cell.

A subgroup of hyperplastic polyps, sessile serrated adenomas, were previously regarded as not giving increased risk of colorectal carcinoma development [19]. An equivalent to the adenoma-carcinoma sequence has been suggested for these adenomas [22], of which an activating mutation in the $B R A F$ gene is regarded as the initiating event of the malignant transformation. Furthermore, methylation of promoter regions resulting in epigenetic silencing of a number of genes is observed in these lesions, the so-called CIMP phenotype. The $M L H 1$ gene is one of the genes frequently shown to be methylated, and abrogation of the normal function of $M L H 1$ will eventually cause MSI tumors. The observation that sessile serrated adenomas gives rise to CIMP and MSI tumors are supported by the fact that these polyps are most frequently found in the right colon $[23,24]$.

Figure 1. Signaling pathways frequently found to be changed in colorectal cancer [25].

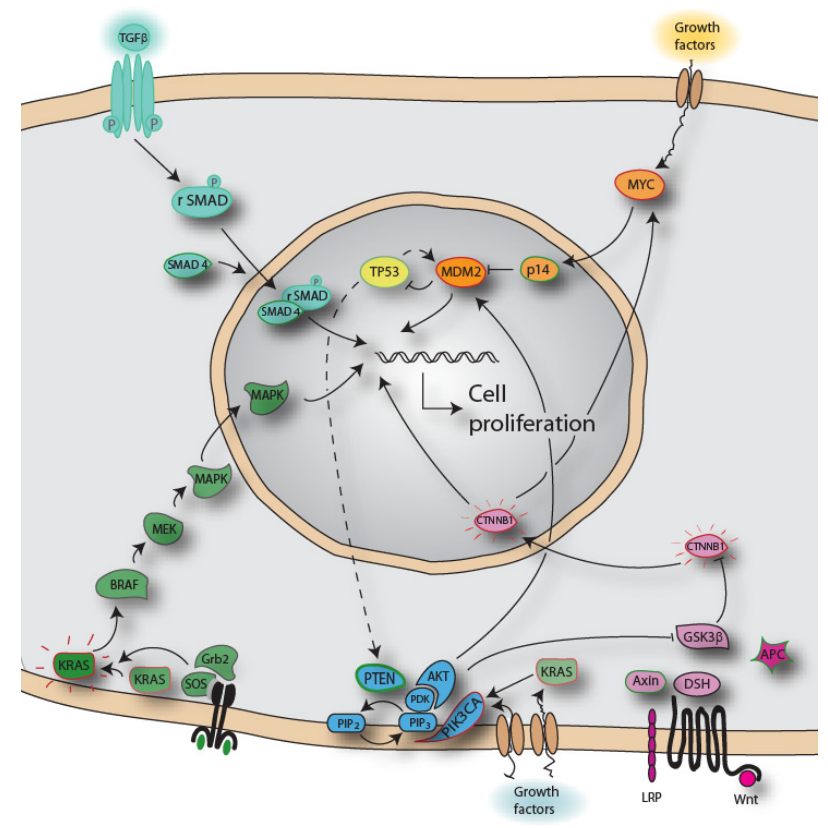

Genes found to be mutated in cancer cells have been defined as either proto-oncogenes or tumor suppressor genes. The proto-oncogenes are promoting cell growth, and when mutated the proliferation rate in the cell is high even in the absence of growth signals. In contrast, mutant tumor suppressor genes are deprived of their cell cycle regulatory function, resulting in cell proliferation even if severe 
damages are introduced in the cell-thus, the normal regulation and balance between apoptosis and proliferation is skewed towards an uncontrolled proliferative state with loss of cell death. However, several more hallmarks are needed for a cancer cell to sustain its growth, expand, invade and ultimately seed and soil its metastatic cells in distant organ sites.

Sjoblom et al. [26] and Wood et al. [27] reported that around 70 genes on average are mutated in a colorectal tumor sample, of which $\sim 10$ are likely to drive tumorigenesis, based on sequencing of 13,023 protein coding genes. Later, Timmermann et al. [12] performed exome sequencing (16,755 RefSeq genes) of MSI and microsatellite stable (MSS) CRCs, and compared the mutation pattern in each tumor to normal colonic mucosa from the same patient. This highlighted specific mutation patterns in the two CRC subtypes, and 359 and 45 functionally significant mutations were reported in MSI and MSS tumors, respectively, which confirms MSI as the mutator phenotype. Furthermore, the BMPR1A gene, mutated in germline cells in juvenile polyposis, was found to be mutated in both MSI and MSS tumors, indicating that this gene might also have an important function in sporadic CRC development.

\section{Biomarkers}

The growing insight in molecular mechanisms of cancers has increased the expectations of these aberrations and compounds to be used as biomarkers. A plethora of molecules have been suggested as markers for risk, diagnosis, prognosis and treatment response, Table 1. But so far, mutations in the oncogene $K R A S$ is the only biomarker in routine clinical use in CRC, validated to have information predicting response to treatment, [28].

Table 1. Type of biomarkers, and examples of biomarkers in use/suggested for use in colorectal cancer.

\begin{tabular}{|c|c|c|c|}
\hline Type of Biomarker & Objective for use & Biological marker & References \\
\hline Risk stratification & $\begin{array}{l}\text { Assess the likelihood that cancers } \\
\text { will develop }\end{array}$ & $\begin{array}{l}\text { APC, AXIN2, BMPR1A, SMAD4, } \\
\text { MUTYH, MSH2, MLH1, MSH6, PMS2, } \\
\text { STK11, PTEN, EPCAM, 8q24, 15q13.3, } \\
\text { SMAD7, LOC120376 }\end{array}$ & [29-40] \\
\hline Screening & $\begin{array}{l}\text { Detect cancers in the } \\
\text { asymptomatic population }\end{array}$ & Stool tests, blood based tests & [41] \\
\hline Diagnosis & $\begin{array}{l}\text { Definitively establish the presence } \\
\text { of cancer }\end{array}$ & $\begin{array}{l}\text { Vimentin (ColoSure *), SEPT9 } \\
(\text { ColoVantage *), miR-17-3p, miR-92 }\end{array}$ & {$[42-44]$} \\
\hline Classification & Classify patients by disease subset & MSI, CIN, CIMP & \\
\hline Prognosis & $\begin{array}{l}\text { Predict the probable outcome of } \\
\text { cancer regardless of therapy }\end{array}$ & $\begin{array}{l}\text { MSI, 18-gene signature (ColoPrint *), } \\
\text { 12-gene signature (OncoType DX } * \text {, } \\
\text { GCC expression (Previstage } * \text { ), miR-21 }\end{array}$ & [45-53] \\
\hline $\begin{array}{l}\text { Prediction/treatment } \\
\text { stratification }\end{array}$ & $\begin{array}{l}\text { Predict response to particular } \\
\text { therapies and choose the drug that is } \\
\text { mostly likely to yield a favorable } \\
\text { response in a given patient }\end{array}$ & $\begin{array}{l}\text { EGFR, KRAS, BRAF, PIK3CA, PTEN, } \\
\text { TP53, miR-140 } \\
\text { Panel (TP53, KRAS, CCDN1, MTHFR) }\end{array}$ & {$[54-56]$} \\
\hline
\end{tabular}

Abbreviations; MSI: microsatellite instability, CIN: Chromosomal instability, CIMP: CpG island methylator phenotype; * Details of biomarkers used are specified in Supplementary Table 1. 


\subsection{Markers Aiding in Prediction of Risk}

Familial syndromes are estimated to cause $25 \%$ of colorectal cancer, but only around $5 \%$ of colorectal cancers are identified to have a known genetic defect [57]. The best described syndromes are Lynch syndrome (aka Hereditary Non-Polyposis Colorectal Cancer, HNPCC), developed on a background of an inherited germline defect DNA-mismatch repair systems leading to widespread MSI, and the Familial Adenomatous Polyposis (FAP) syndrome, caused by germline mutations in the APC gene. HNPCC is clinically associated with other cancers such as gastric and endometric cancer but no widespread development of colonic polyps despite cancer development at an early age ( $<50$ years). FAP patients however, develop polyps in hundreds and thousands, necessitating total colectomy often at or before the age of 20 to avoid malignant transformation. Although most patients do not fall into one of these two hereditary categories, many patients may have family members with the disease, despite no clear cut genetic association found. However, to date, several genes are known to harbor mutations causing hereditary syndromes involving colorectal cancer [58-60].

In addition to inherited mutations, a number of chromosomal locations and single nucleotide polymorphisms (SNPs) have been suggested as having increased risk for CRC development, but few have been validated in larger cohorts. However, in 8q24 [34-37], 15q13.3 [29,37,38], SMAD7 [32,37,39,40], and LOC120376 [33,37,39], SNPs have been validated, and each of them shown to be associated with increased risk of CRC development. Furthermore, if the SNP is located in a miRNA target site it might interfere binding, resulting in changes in gene and protein expression. More aberrations, especially those causing disease in a recessive manner, are predicted to be discovered in the future.

\subsection{Diagnostic Markers}

Early detection of colorectal cancer is pivotal for a good outcome of the disease. The fecal occult blood test (FOBT) is a non-invasive diagnostic test based on detection of blood in the feces. The test has shown low sensitivity and specificity, especially for early disease stages, as not all cancers bleed, and bleeding can be caused by other conditions than cancer. Whether the test reduces mortality is debated [61], although at least three large randomized controlled trials have demonstrated a reduction in cancer-specific mortality with the use of FOBT. A further drawback is the need for invasive follow up (usually by colonoscopy) for positive findings. Screening populations using colonoscopy or sigmoidoscopy is expensive and unpleasant for the individual, which reduces the compliance among patients. Further colonoscopy is associated with a small but relevant risk for adverse event (perforation during the procedure) which may indeed be life-threatening. "Virtual colonography" or CT colonography has been proposed as a non-invasive alternative, but introduces the risk of radiation exposure, and again, a number of follow up test will be needed to investigate positive findings. Consequently, the need for better and preferably less invasive tests are warranted. Testing for changes in methylation pattern in feces and blood samples have shown improvements in sensitivity and specificity compared to the FOBT test $[61,62]$. The commercially available test ColoSure ${ }^{\mathrm{TM}}$ examines methylation in the Vimentin gene in feces samples, for early diagnosis of CRC [63,64]. Although its sensitivity (77\%) and specificity $(83 \%)$ is enhanced compared to FOBT, detection rates have not been assessed in a normal 
population and its clinical utility is therefore not established [42]. Panels of methylated genes have been recognized in feces samples, in which increased sensitivity and specificity of colorectal tumors are identified $[65,66]$.

The presence of methylation of the Septin9 (SEPT9) gene has been shown to be highly correlated to occurrence of colorectal tumor cells. [67] Testing for methylation of SEPT9 in plasma has been commercialized as ColoVantage ${ }^{\mathrm{TM}}$.

Using dysregulation of the expression of circulating miRNAs as markers for early diagnosis has gained more attention over the last years. In a study by $\mathrm{Ng}$ et al., elevated levels of miR-17-3p and miR-92 were reported to be statistically significant compared to the levels in healthy individuals, and also compared to gastric cancer and inflammatory bowel disease [44].

\subsection{Prognostic Markers}

Even if meta-analyses have clearly shown a better prognosis of MSI cancers compared to CIN [68], clinical and histopathological data is still used as the main prognosticator and basis for treatment regime in CRC. The outcome of patients at disease stage II and III is however difficult to predict. Especially, for stage II cancers, defined on the basis of not finding metastases in lymph nodes, which could be erroneous, as a pathologist will not have the possibility to investigate all cells in all resected lymph nodes. Gene expression of GCC in tissue from lymph nodes has shown a good correlation to disease outcome, refining correct staging of stage II patients. The test is available as a commercial test manufactured as Previstage [51]. A more precise separation of stage II and III CRCs in high- and low risk groups have been obtained using mRNA expression profiles of 18 genes, commercialized as ColoPrint, Table 2 [46]. Yet another commercially available test, (OncoType DX), uses mRNA expression profile of 12 genes in order to indicate a risk of relapse in stage II patients [48]. Also, expression of miR-21 has been shown to be correlated to poor survival and therapeutic outcome in stage II and III CRCs [52], as well as being an independent predictor of overall survival in CRC [53].

Table 2. Details of commercially available tests.

\begin{tabular}{|c|c|c|}
\hline Test name & Biological material & Biomarker(s) \\
\hline ColoSure $^{\mathrm{TM}}$ & Methylated DNA in feces & Vimentin \\
\hline ColoVantage ${ }^{\circledR}$ & Methylated DNA in plasma & SEPT9 \\
\hline ColoPrint $\AA$ & $\begin{array}{l}\text { mRNA expression in tumor } \\
\text { tissue }\end{array}$ & $\begin{array}{l}\text { MCTP1, LAMA3, CTSC, PYROX D1, EDEM1, } \\
\text { IL2RB, ZNF697, SLC6A11, IL2RA, CYFIP 2, } \\
\text { PIM3, LIF, PLIN3, HSD3B1, ZBED4, PPARA, } \\
\text { THNSL2, CA4388O2 }\end{array}$ \\
\hline OncoType & mRNA expression in tumor & Ki-67, C-MYC, MYBL2, FAP, BGN, INHBA, \\
\hline $\mathrm{DX} \AA$ & tissue & GADD45B, ATP5E, PGK1, GPX1, UBB, VDAC2 \\
\hline Previstage $^{\mathrm{TM}}$ & $\begin{array}{l}\text { mRNA expression in lymph } \\
\text { node tissue }\end{array}$ & $G C C(G U C Y 2 C)$ \\
\hline
\end{tabular}

\subsection{Predictive Markers}

The KRAS proto-oncogene is a molecular switch that controls cellular proliferation and differentiation, and its activation through EGFR is of essence for its proliferative effect in CRC. 
Overexpression, amplification and mutations of EGFR, resulting in signalling through the MAPK and PI3K pathways, are frequent in CRC, and it is therefore a good target for treatment of CRC. For metastatic colorectal cancer (mCRC) treatment by EGFR-targeted drugs is one of few therapeutic alternatives. However, when EGFRs downstream effector KRAS is mutated, it becomes constitutively active, the MAPK pathway is constantly switched on, and thus, treatment targeting EGFR will fail. Furthermore, only $\sim 30 \%$ of the wild-type KRAS patients benefit from this treatment [69]. This indicates that other downstream effectors of the MAPK pathway or the PI3K pathway might have activating mutations. There are increasing evidences that the V600E mutation in the BRAF gene also inhibits effective treatment with anti-EGFR-therapies [69,70]. Furthermore, mutations in the PIK3CA gene, and overexpression of PTEN have also been associated with lack of response, and a combined analysis of these four genes would predict outcome in $70 \%$ of the patients [71]. Another theory that has been suggested for the lack of effect in KRAS wt samples, is heterogeneity within the tumor and between primary tumor and metastasis [72,73].

A panel of markers has recently been published to be associated with resistance to neoadjuvant chemoradiation therapy in rectal cancer [55]. The mutation profile of 23 genes was studied, and correlated to patient response to chemoradiation determined, in order to identify which patients will benefit from this treatment. Using a subset of four markers (TP53, KRAS, CCND1 and MTHFR), they report a specificity of $97 \%$, and a sensitivity of $52 \%$ for predicting patients without pathologic complete response. This implies a possibility to predict which patients will be resistant to chemoradiation therapy, and spare these patients unwanted side-effects [41].

Despite the fact that the knowledge of miRNA's existence is few than 20 years, their function has been linked to anticancer chemotherapy in model systems. Resistance to 5-FU and methotrexate has been associated with expression of the miRNA miR-140 in the HCT116 cell line [56].

\section{Conclusions and the Way Forward}

Colorectal cancer most frequently develops sporadically, and at an increasing rate also in young patients ( $<50$ years), although the highest prevalence still occurs in those aged 60-70 years. As patients having a localized disease stage at time of surgery have a very favorable prognosis, the early detection of the disease represents a compelling opportunity to reduce the disease burden. Clinical symptoms are non-specific, or unnoticeable at early disease stages, therefore there is a need for modes of early detection to reduce morbidity and mortality of the disease. Colonoscopy is still the golden standard in detecting aberrant lesions, but expensive and unpleasant for the patient. The excitement regarding blood and stool-based tests has therefore been great, but to date these tests have shown poor sensitivity and specificity compared to colonoscopy.

Over the last decade, large-scale technology has been implemented in the search for deviations underlying diseases. Despite initial optimism regarding the output from these analyses, findings have not revolutionized the field of colorectal cancer yet. First and foremost this technology is hypothesisgenerating. Findings must be validated, e.g., with different downstream analysis tools; in new patient sample sets; and, with other methods, before robust implementation of biomarkers in the clinic can be recommended. The most recent advance in the large-scale technology field is the next-generation sequencing methodology. Identification of variants and mutations in an individual tumor will add 
information to the type of cancer and refine classification of the specific tumor. Also, a comparison of the whole genome sequence of normal cells from the tumor bearing individual will reveal tumor-specific aberrations. In total this can be utilized as prognostic and predictive tools in a clinical setting, and as information supporting a more personalized treatment. However, as knowledge about additional mechanisms of impairing cell signaling, such as molecular modification of DNA (e.g., methylation), regulation of mRNA and protein generation (e.g., miRNA), redundant pathways and genetic mechanisms has emerged, the realization that mutation screening solely will probably not reveal outcome of disease and treatment has also dawned.

Several genes and pathways affected by changes have been identified in colorectal tumors, and the knowledge about initiation and progression of the disease is extensive. Also, the number of published articles aiming at using this knowledge as biomarkers is numerous. However, the implementation of this knowledge into clinical practice is so far limited. To date, testing the gene $K R A S$ for activating mutations is in routine clinical use, as it has been shown to have predictive information in relation to treatment with antibodies against the EGFR-receptor. Findings reported in the literature support additional testing of $B R A F, P T E N$ and PIK3CA before anti-EGFR treatment in metastatic colorectal cancer. On the other hand, there is an increasing panel of treatments that have been designed to target specific genes and pathways, which further highlights the role of normally functioning genes in order for the drug to have the desired effect in the patient.

As more biomarkers are identified and validated it is anticipated that these will be used more extensively in clinical decision making. Optimization of tools to predict the risk for developing cancer, diagnose a disease at an early stage, give a prognosis that is as correct as possible, and predict treatment response in the patient, is of invaluable significance. First and foremost this applies to the patient itself, but also to the health personnel, and in a socioeconomic perspective.

\section{Acknowledgments}

Funded in part by grants from the Folke Hermansens Cancer Foundation (grant \#424508).

\section{References}

1. Markowitz, S.D.; Bertagnolli, M.M. Molecular origins of cancer: Molecular basis of colorectal cancer. N. Engl. J. Med. 2009, 361, 2449-2460.

2. Lengauer, C.; Kinzler, K.W.; Vogelstein, B. Genetic instability in colorectal cancers. Nature 1997, 386, 623-627.

3. Rajagopalan, H.; Nowak, M.A.; Vogelstein, B.; Lengauer, C. The significance of unstable chromosomes in colorectal cancer. Nat. Rev. Cancer 2003, 3, 695-701.

4. Barber, T.D.; McManus, K.; Yuen, K.W.; Reis, M.; Parmigiani, G.; Shen, D.; Barrett, I.; Nouhi, Y.; Spencer, F.; Markowitz, S.; et al. Chromatid cohesion defects may underlie chromosome instability in human colorectal cancers. Proc. Natl. Acad. Sci. USA 2008, 105, 3443-3448.

5. Thompson, S.L.; Bakhoum, S.F.; Compton, D.A. Mechanisms of chromosomal instability. Curr. Biol. 2010, 20, R285-R295.

6. Soreide, K.; Janssen, E.A.; Soiland, H.; Korner, H.; Baak, J.P. Microsatellite instability in colorectal cancer. Br. J. Surg. 2006, 93, 395-406. 
7. Baylin, S.B.; Hoppener, J.W.; de Bustros, A.; Steenbergh, P.H.; Lips, C.J.; Nelkin, B.D. DNA methylation patterns of the calcitonin gene in human lung cancers and lymphomas. Cancer Res. 1986, 46, 2917-2922.

8. Toyota, M.; Ahuja, N.; Ohe-Toyota, M.; Herman, J.G.; Baylin, S.B.; Issa, J.P. Cpg island methylator phenotype in colorectal cancer. Proc. Natl. Acad. Sci. USA 1999, 96, 8681-8686.

9. Walther, A.; Johnstone, E.; Swanton, C.; Midgley, R.; Tomlinson, I.; Kerr, D. Genetic prognostic and predictive markers in colorectal cancer. Nat. Rev. Cancer 2009, 9, 489-499.

10. Sastre, L. New DNA sequencing technologies open a promising era for cancer research and treatment. Clin. Transl. Oncol. 2011, 13, 301-306.

11. Chang, H.; Jackson, D.G.; Kayne, P.S.; Ross-Macdonald, P.B.; Ryseck, R.P.; Siemers, N.O. Exome sequencing reveals comprehensive genomic alterations across eight cancer cell lines. PLoS One 2011, 6, e21097.

12. Timmermann, B.; Kerick, M.; Roehr, C.; Fischer, A.; Isau, M.; Boerno, S.T.; Wunderlich, A.; Barmeyer, C.; Seemann, P.; Koenig, J.; et al. Somatic mutation profiles of msi and mss colorectal cancer identified by whole exome next generation sequencing and bioinformatics analysis. PLoS One 2010, 5, e15661.

13. Curtin, K.; Slattery, M.L.; Samowitz, W.S. Cpg island methylation in colorectal cancer: Past, present and future. Patholog. Res. Int. 2011, 2011, 902674:1-902674:8.

14. Schee, K.; Fodstad, O.; Flatmark, K. Micrornas as biomarkers in colorectal cancer. Am. J. Pathol. 2010, 177, 1592-1599.

15. van Kouwenhove, M.; Kedde, M.; Agami, R. Microrna regulation by rna-binding proteins and its implications for cancer. Nat. Rev. Cancer 2011, 11, 644-656.

16. de Krijger, I.; Mekenkamp, L.J.; Punt, C.J.; Nagtegaal, I.D. Micrornas in colorectal cancer metastasis. J. Pathol. 2011, 224, 438-447.

17. Schwarzenbach, H.; Hoon, D.S.; Pantel, K. Cell-free nucleic acids as biomarkers in cancer patients. Nat. Rev. Cancer 2011, 11, 426-437.

18. Jones, S.J.; Laskin, J.; Li, Y.Y.; Griffith, O.L.; An, J.; Bilenky, M.; Butterfield, Y.S.; Cezard, T.; Chuah, E.; Corbett, R.; et al. Evolution of an adenocarcinoma in response to selection by targeted kinase inhibitors. Genome Biol. 2010, 11, R82.

19. Torlakovic, E.; Snover, D.C. Serrated adenomatous polyposis in humans. Gastroenterology 1996, $110,748-755$.

20. Fearon, E.R.; Vogelstein, B. A genetic model for colorectal tumorigenesis. Cell 1990, 61, 759-767.

21. Laurent-Puig, P.; Blons, H.; Cugnenc, P.H. Sequence of molecular genetic events in colorectal tumorigenesis. Eur. J. Cancer Prev. 1999, 8, S39-S47.

22. Snover, D.C.; Jass, J.R.; Fenoglio-Preiser, C.; Batts, K.P. Serrated polyps of the large intestine: A morphologic and molecular review of an evolving concept. Am. J. Clin. Pathol. 2005, 124, 380-391.

23. O’Brien, M.J.; Yang, S.; Mack, C.; Xu, H.; Huang, C.S.; Mulcahy, E.; Amorosino, M.; Farraye, F.A. Comparison of microsatellite instability, cpg island methylation phenotype, braf and kras status in serrated polyps and traditional adenomas indicates separate pathways to distinct colorectal carcinoma end points. Am. J. Surg. Pathol. 2006, 30, 1491-1501. 
24. Kim, K.M.; Lee, E.J.; Ha, S.; Kang, S.Y.; Jang, K.T.; Park, C.K.; Kim, J.Y.; Kim, Y.H.; Chang, D.K.; Odze, R.D. Molecular features of colorectal hyperplastic polyps and sessile serrated adenoma/polyps from korea. Am. J. Surg. Pathol. 2011, 35, 1274-1286.

25. Berg, M. Genomics of Colorectal Carcinomas from Young and Elderly Patients. Ph.D. Thesis, University of Oslo, Oslo, Norway, 2010.

26. Sjoblom, T.; Jones, S.; Wood, L.D.; Parsons, D.W.; Lin, J.; Barber, T.; Mandelker, D.; Leary, R.J.; Ptak, J.; Silliman, N.; et al. The consensus coding sequences of human breast and colorectal cancers. Science 2006, 314, 268-274.

27. Wood, L.D.; Parsons, D.W.; Jones, S.; Lin, J.; Sjoblom, T.; Leary, R.J.; Shen, D.; Boca, S.M.; Barber, T.; Ptak, J.; et al. The genomic landscapes of human breast and colorectal cancers. Science 2007, 318, 1108-1113.

28. Allegra, C.J.; Jessup, J.M.; Somerfield, M.R.; Hamilton, S.R.; Hammond, E.H.; Hayes, D.F.; McAllister, P.K.; Morton, R.F.; Schilsky, R.L. American society of clinical oncology provisional clinical opinion: Testing for kras gene mutations in patients with metastatic colorectal carcinoma to predict response to anti-epidermal growth factor receptor monoclonal antibody therapy. J. Clin. Oncol. 2009, 27, 2091-2096.

29. Jaeger, E.; Webb, E.; Howarth, K.; Carvajal-Carmona, L.; Rowan, A.; Broderick, P.; Walther, A.; Spain, S.; Pittman, A.; Kemp, Z.; et al. Common genetic variants at the crac1 (hmps) locus on chromosome 15q13.3 influence colorectal cancer risk. Nat. Genet. 2008, 40, 26-28.

30. Migliore, L.; Migheli, F.; Spisni, R.; Coppede, F. Genetics, cytogenetics, and epigenetics of colorectal cancer. J. Biomed. Biotechnol. 2011, $2011,792362$.

31. Bacolod, M.D.; Barany, F. Molecular profiling of colon tumors: The search for clinically relevant biomarkers of progression, prognosis, therapeutics, and predisposition. Ann. Surg. Oncol. 2011, $18,3694-3700$.

32. Broderick, P.; Carvajal-Carmona, L.; Pittman, A.M.; Webb, E.; Howarth, K.; Rowan, A.; Lubbe, S.; Spain, S.; Sullivan, K.; Fielding, S.; et al. A genome-wide association study shows that common alleles of smad7 influence colorectal cancer risk. Nat. Genet. 2007, 39, 1315-1317.

33. Pittman, A.M.; Webb, E.; Carvajal-Carmona, L.; Howarth, K.; Di Bernardo, M.C.; Broderick, P.; Spain, S.; Walther, A.; Price, A.; Sullivan, K.; et al. Refinement of the basis and impact of common 11q23.1 variation to the risk of developing colorectal cancer. Hum. Mol. Genet. 2008, $17,3720-3727$.

34. Zanke, B.W.; Greenwood, C.M.; Rangrej, J.; Kustra, R.; Tenesa, A.; Farrington, S.M.; Prendergast, J.; Olschwang, S.; Chiang, T.; Crowdy, E.; et al. Genome-wide association scan identifies a colorectal cancer susceptibility locus on chromosome 8q24. Nat. Genet. 2007, 39, 989-994.

35. Haiman, C.A.; Le, M.L.; Yamamato, J.; Stram, D.O.; Sheng, X.; Kolonel, L.N.; Wu, A.H.; Reich, D.; Henderson, B.E. A common genetic risk factor for colorectal and prostate cancer. Nat. Genet. 2007, 39, 954-956.

36. Tomlinson, I.; Webb, E.; Carvajal-Carmona, L.; Broderick, P.; Kemp, Z.; Spain, S.; Penegar, S.; Chandler, I.; Gorman, M.; Wood, W.; et al. A genome-wide association scan of tag snps identifies a susceptibility variant for colorectal cancer at 8q24.21. Nat. Genet. 2007, 39, 984-988. 
37. He, J.; Wilkens, L.R.; Stram, D.O.; Kolonel, L.N.; Henderson, B.E.; Wu, A.H.; Le, M.L.; Haiman, C.A. Generalizability and epidemiologic characterization of eleven colorectal cancer gwas hits in multiple populations. Cancer Epidemiol. Biomark. Prev. 2011, 20, 70-81.

38. Houlston, R.S.; Webb, E.; Broderick, P.; Pittman, A.M.; Di Bernardo, M.C.; Lubbe, S.; Chandler, I.; Vijayakrishnan, J.; Sullivan, K.; Penegar, S.; et al. Meta-analysis of genome-wide association data identifies four new susceptibility loci for colorectal cancer. Nat. Genet. 2008, 40, 1426-1435.

39. Tenesa, A.; Farrington, S.M.; Prendergast, J.G.; Porteous, M.E.; Walker, M.; Haq, N.; Barnetson, R.A.; Theodoratou, E.; Cetnarskyj, R.; Cartwright, N.; et al. Genome-wide association scan identifies a colorectal cancer susceptibility locus on 11q23 and replicates risk loci at 8q24 and 18q21. Nat. Genet. 2008, 40, 631-637.

40. Tomlinson, I.P.; Webb, E.; Carvajal-Carmona, L.; Broderick, P.; Howarth, K.; Pittman, A.M.; Spain, S.; Lubbe, S.; Walther, A.; Sullivan, K.; et al. A genome-wide association study identifies colorectal cancer susceptibility loci on chromosomes 10p14 and 8q23.3. Nat. Genet. 2008, 40, 623-630.

41. Bosch, L.J.; Carvalho, B.; Fijneman, R.J.; Jimenez, C.R.; Pinedo, H.M.; van, E.M.; Meijer, G.A. Molecular tests for colorectal cancer screening. Clin. Colorectal Cancer 2011, 10, 8-23.

42. Ned, R.M.; Melillo, S.; Marrone, M. Fecal DNA testing for colorectal cancer screening: The colosure test. PLoS Curr. 2011, 3, doi:10.1371/currents.RRN1220.

43. Lofton-Day, C.; Model, F.; deVos, T.; Tetzner, R.; Distler, J.; Schuster, M.; Song, X.; Lesche, R.; Liebenberg, V.; Ebert, M.; et al. DNA methylation biomarkers for blood-based colorectal cancer screening. Clin. Chem. 2008, 54, 414-423.

44. Ng, E.K.; Chong, W.W.; Jin, H.; Lam, E.K.; Shin, V.Y.; Yu, J.; Poon, T.C.; Ng, S.S.; Sung, J.J. Differential expression of micrornas in plasma of patients with colorectal cancer: A potential marker for colorectal cancer screening. Gut 2009, 58, 1375-1381.

45. Deschoolmeester, V.; Baay, M.; Specenier, P.; Lardon, F.; Vermorken, J.B. A review of the most promising biomarkers in colorectal cancer: One step closer to targeted therapy. Oncologist 2010, 15, 699-731.

46. Tan, I.B.; Tan, P. Genetics: An 18-gene signature (coloprint(r)) for colon cancer prognosis. Nat. Rev. Clin. Oncol. 2011, 8, 131-133.

47. Salazar, R.; Roepman, P.; Capella, G.; Moreno, V.; Simon, I.; Dreezen, C.; Lopez-Doriga, A.; Santos, C.; Marijnen, C.; Westerga, J.; et al. Gene expression signature to improve prognosis prediction of stage ii and iii colorectal cancer. J. Clin. Oncol. 2011, 29, 17-24.

48. Clark-Langone, K.M.; Sangli, C.; Krishnakumar, J.; Watson, D. Translating tumor biology into personalized treatment planning: Analytical performance characteristics of the oncotype $\mathrm{dx}$ colon cancer assay. BMC Cancer 2010, 10, 691.

49. Webber, E.M.; Lin, J.S.; Evelyn, P.W. Oncotype dx tumor gene expression profiling in stage ii colon cancer. Application: Prognostic, risk prediction. PLoS Curr. 2010, 2, doi:10.1371/currents.RRN1177.

50. Mejia, A.; Waldmana, S.A. Previstage gec test for staging patients with colorectal cancer. Expert Rev. Mol. Diagn. 2008, 8, 571-578. 
51. Carlson, M.R. Previstage gec colorectal cancer staging test: A new molecular test to identify lymph node metastases and provide more accurate information about the stage of patients with colorectal cancer. Mol. Diagn. Ther. 2009, 13, 11-14.

52. Guo, C.; Sah, J.F.; Beard, L.; Willson, J.K.; Markowitz, S.D.; Guda, K. The noncoding rna, mir-126, suppresses the growth of neoplastic cells by targeting phosphatidylinositol 3-kinase signaling and is frequently lost in colon cancers. Genes Chromosomes Cancer 2008, 47, 939-946.

53. Schetter, A.J.; Leung, S.Y.; Sohn, J.J.; Zanetti, K.A.; Bowman, E.D.; Yanaihara, N.; Yuen, S.T.; Chan, T.L.; Kwong, D.L.; Au, G.K.; et al. Microrna expression profiles associated with prognosis and therapeutic outcome in colon adenocarcinoma. JAMA 2008, 299, 425-436.

54. Ross, J.S.; Torres-Mora, J.; Wagle, N.; Jennings, T.A.; Jones, D.M. Biomarker-based prediction of response to therapy for colorectal cancer: Current perspective. Am. J. Clin. Pathol. 2010, 134, 478-490.

55. Garcia-Aguilar, J.; Chen, Z.; Smith, D.D.; Li, W.; Madoff, R.D.; Cataldo, P.; Marcet, J.; Pastor, C. Identification of a biomarker profile associated with resistance to neoadjuvant chemoradiation therapy in rectal cancer. Ann. Surg. 2011, 254, 486-493.

56. Song, B.; Wang, Y.; Xi, Y.; Kudo, K.; Bruheim, S.; Botchkina, G.I.; Gavin, E.; Wan, Y.; Formentini, A.; Kornmann, M.; et al. Mechanism of chemoresistance mediated by mir-140 in human osteosarcoma and colon cancer cells. Oncogene 2009, 28, 4065-4074.

57. Jasperson, K.W.; Tuohy, T.M.; Neklason, D.W.; Burt, R.W. Hereditary and familial colon cancer. Gastroenterology 2010, 138, 2044-2058.

58. Vogelstein, B.; Kinzler, K.W. Cancer genes and the pathways they control. Nat. Med. 2004, 10, 789-799.

59. Gruber, S.B.; Ellis, N.A.; Scott, K.K.; Almog, R.; Kolachana, P.; Bonner, J.D.; Kirchhoff, T.; Tomsho, L.P.; Nafa, K.; Pierce, H.; et al. Blm heterozygosity and the risk of colorectal cancer. Science 2002, 297, 2013.

60. Ligtenberg, M.J.; Kuiper, R.P.; Chan, T.L.; Goossens, M.; Hebeda, K.M.; Voorendt, M.; Lee, T.Y.; Bodmer, D.; Hoenselaar, E.; Hendriks-Cornelissen, S.J.; et al. Heritable somatic methylation and inactivation of msh2 in families with lynch syndrome due to deletion of the $3^{\prime}$ exons of tacstd1. Nat. Genet. 2009, 41, 112-117.

61. Ekelund, G.; Manjer, J.; Zackrisson, S. Population-based screening for colorectal cancer with faecal occult blood test--do we really have enough evidence? Int. J. Colorectal Dis. 2010, 25, 1269-1275.

62. Lenhard, K.; Bommer, G.T.; Asutay, S.; Schauer, R.; Brabletz, T.; Goke, B.; Lamerz, R.; Kolligs, F.T. Analysis of promoter methylation in stool: A novel method for the detection of colorectal cancer. Clin. Gastroenterol. Hepatol. 2005, 3, 142-149.

63. Itzkowitz, S.; Brand, R.; Jandorf, L.; Durkee, K.; Millholland, J.; Rabeneck, L.; Schroy, P.C., III; Sontag, S.; Johnson, D.; Markowitz, S.; et al. A simplified, noninvasive stool DNA test for colorectal cancer detection. Am. J. Gastroenterol. 2008, 103, 2862-2870.

64. Itzkowitz, S.H.; Jandorf, L.; Brand, R.; Rabeneck, L.; Schroy, P.C., III.; Sontag, S.; Johnson, D.; Skoletsky, J.; Durkee, K.; Markowitz, S.; et al. Improved fecal DNA test for colorectal cancer screening. Clin. Gastroenterol. Hepatol. 2007, 5, 111-117. 
65. Azuara, D.; Rodriguez-Moranta, F.; de, O.J.; Soriano-Izquierdo, A.; Mora, J.; Guardiola, J.; Biondo, S.; Blanco, I.; Peinado, M.A.; Moreno, V.; et al. Novel methylation panel for the early detection of colorectal tumors in stool DNA. Clin. Colorectal Cancer 2010, 9, 168-176.

66. Lind, G.E.; Danielsen, S.A.; Ahlquist, T.; Merok, M.A.; Andresen, K.; Skotheim, R.I.; Hektoen, M.; Rognum, T.O.; Meling, G.I.; Hoff, G.; et al. Identification of an epigenetic biomarker panel with high sensitivity and specificity for colorectal cancer and adenomas. Mol. Cancer 2011, 10, 85.

67. Model, F.; Osborn, N.; Ahlquist, D.; Gruetzmann, R.; Molnar, B.; Sipos, F.; Galamb, O.; Pilarsky, C.; Saeger, H.D.; Tulassay, Z.; et al. Identification and validation of colorectal neoplasia-specific methylation markers for accurate classification of disease. Mol. Cancer Res. 2007, 5, 153-163.

68. Guastadisegni, C.; Colafranceschi, M.; Ottini, L.; Dogliotti, E. Microsatellite instability as a marker of prognosis and response to therapy: A meta-analysis of colorectal cancer survival data. Eur. J. Cancer 2010, 46, 2788-2798.

69. Bardelli, A.; Siena, S. Molecular mechanisms of resistance to cetuximab and panitumumab in colorectal cancer. J. Clin. Oncol. 2010, 28, 1254-1261.

70. Samowitz, W.S.; Sweeney, C.; Herrick, J.; Albertsen, H.; Levin, T.R.; Murtaugh, M.A.; Wolff, R.K.; Slattery, M.L. Poor survival associated with the braf v600e mutation in microsatellite-stable colon cancers. Cancer Res. 2005, 65, 6063-6069.

71. Sartore-Bianchi, A.; Di, N.F.; Nichelatti, M.; Molinari, F.; De, D.S.; Saletti, P.; Martini, M.; Cipani, T.; Marrapese, G.; Mazzucchelli, L.; et al. Multi-determinants analysis of molecular alterations for predicting clinical benefit to egfr-targeted monoclonal antibodies in colorectal cancer. PLoS One 2009, 4, e7287.

72. Li, Z.; Jin, K.; Lan, H.; Teng, L. Heterogeneity in primary colorectal cancer and its corresponding metastases: A potential reason of egfr-targeted therapy failure? Hepatogastroenterology 2011, 58, 411-416.

73. Oltedal, S.; Aasprong, O.G.; Moller, J.H.; Korner, H.; Gilje, B.; Tjensvoll, K.; Birkemeyer, E.M.; Heikkila, R.; Smaaland, R.; Nordgard, O. Heterogeneous distribution of k-ras mutations in primary colon carcinomas: Implications for egfr-directed therapy. Int. J. Colorectal Dis. 2011, 26, 1271-1277.

(C) 2011 by the authors; licensee MDPI, Basel, Switzerland. This article is an open access article distributed under the terms and conditions of the Creative Commons Attribution license (http://creativecommons.org/licenses/by/3.0/). 